\title{
Correlation of cytotoxicity with elemental release from mercury- and gallium-based dental alloys in vitro
}

\author{
John C. Wataha', Hiroshi Nakajima ${ }^{2}$, Carl T. Hanks ${ }^{3}$, Toru Okabe ${ }^{2}$ \\ ${ }^{1}$ Department of Prosthodontics and ${ }^{3}$ Department of Oral Pathology, Medicine and Surgery, \\ The University of Michigan School of Dentistry, Ann Arbor, Michigan, USA \\ ${ }^{2}$ Department of Biomaterials Science, Baylor College of Dentistry, Dallas, Texas, USA
}

\begin{abstract}
Objectives. An in vitro screening test was used to compare the cytotoxicity and elemental release from mercury- and galliumbased dental restorative materials.

Methods. The test employed three sequential extractions of the samples into cell-culture medium which were then used to evaluate the cytotoxicity of the samples and the release of elements from the samples. Cytotoxicity was measured by placing the extract in contact with Balb/c mouse fibroblasts for $24 \mathrm{~h}$ and measuring the succinic dehydrogenase activity of the cells. The release of elements was measured by means of atomic absorption spectrophotometry.

Results. Samples of Tytin (Kerr) showed no cytotoxicity compared to Teflon controls. Dispersalloy (Johnson and Johnson) was severely cytotoxic initially when Zn release was greatest, but was less toxic between 48 and $72 \mathrm{~h}$ as $\mathrm{Zn}$ release decreased. Gallium Alloy GF (Tokuriki Honten) was moderately cytotoxic after $8 \mathrm{~h}$, and increased in cytotoxicity thereafter, which correlated with a substantial and persistent release of Ga from this material.

Significance. The results of the current study concurred with in vivo assessments of these materials, and the use of sequential extractions was useful in determining trends in the cytotoxicity and elemental release from these materials.
\end{abstract}

\section{INTRODUCTION}

Gallium-based alloys were introduced to dentistry in 1956 with the discovery that combinations of gallium and nickel produced a setting mass which was packable and had promising physical properties for oral restorations (Smith and Caul, 1956). Subsequently, alloys of gallium, copper, and tin (Smith et al., 1956), gallium and palladium (Waterstrat and Longton, 1964), and gallium, palladium, and tin (Waterstrat, 1969) were reported. Modern formulations of these materials combine liquid alloys of gallium, indium and tin with a solid alloy of silver, palladium, tin, copper, and zinc (Horibe et al., 1986; Okamoto and Horibe, 1991).

The biological response to gallium-based dental alloys has been of concern since their introduction (Waterstrat and
Longton, 1964; Waterstrat, 1969). Although soluble gallium ions are relatively non-toxic compared to other elements such as cadmium (Kawahara et al., 1968; Ferm and Carpenter, 1970; Domingo et al., 1987), gallium ions significantly disrupt cellular metabolism (Aoki et al., 1990; Wataha et al., 1991). These adverse effects have been used to advantage in the development of Ga-based anti-cancer drugs, which have significant systemic toxicity, especially in the kidneys (Foster et al., 1986). The biological safety of gallium-based dental alloys has been further questioned in light of reports (Lyon et al., 1966; Langeland et al., 1967; Kaga et al., 1992a) which have demonstrated that these alloys elicit moderate to severe inflammatory responses when implanted subcutaneously and disintegrate over 6 mon. Clinically, dental restorations of gallium-based alloys have shown discoloration, tarnish, and roughness over periods of one year (Kim et al., 1988; Yamashita et al., 1989; Den et al., 1991; Navarro et al., 1993; Sakai et al., 1993), which indicates that the in vivo deterioration of these alloys is significant.

New gallium-based alloys are being developed to improve the corrosion and biological properties of the earlier versions of these alloys, but there is a significant need for an in vitro screening test to measure the biological response to new formulations since animal and human experiments are expensive, time consuming, and controversial. There have been several previous reports of attempts to measure the in vitro cytotoxicity of gallium- and mercury-based alloys. Psarras et al. (1992) first exposed the alloys to saline for 1 or $10 \mathrm{wk}$, then tested alloy cytotoxicity indirectly through a filter barrier. They then exposed the samples to cell-culture medium for $24 \mathrm{~h}$ or $7 \mathrm{~d}$ and tested the cytotoxicity of the medium extracts. Although all of the samples caused mild to severe toxicity through the filters, none of the cell-culture extracts was severely cytotoxic; extracts from the specimens corroded for $10 \mathrm{wk}$ were, however, slightly more toxic. The test described is too long to be useful as a screening test, and these authors did not measure the released elements which might be causing the cytotoxic responses.

An in vitro test to measure the cytotoxicity of gallium- 


\begin{tabular}{|c|c|c|c|c|c|c|c|c|c|c|}
\hline \multicolumn{11}{|c|}{ TABLE 1: COMPOSITION OF ALLOYS (WT. \%) } \\
\hline Material & $\begin{array}{c}\text { Batch } \\
\text { Number }\end{array}$ & $\mathrm{Hg}$ & $\mathrm{Ga}$ & $\mathrm{Ag}$ & Sn & $\mathrm{Cu}$ & $\mathrm{Pd}$ & $\ln$ & $\mathrm{Zn}$ & $\begin{array}{c}\text { Powder/Liquid } \\
\text { Ratio }(\mathrm{g} / \mathrm{g})\end{array}$ \\
\hline \multicolumn{11}{|l|}{ Powder: } \\
\hline Gallium Alloy GF & Not Avail. & & & 50.0 & 25.7 & 15.0 & 9.0 & & 0.3 & $1.00 / 0.65$ \\
\hline Dispersalloy* & $\begin{array}{l}180990 \mathrm{~A} \\
0 J 519\end{array}$ & & & 69.6 & 17.7 & 11.8 & & & 0.67 & $1.00 / 1.00$ \\
\hline Tytin & 0601881127 & & & 60.0 & 27.0 & 13.0 & & & & $1.00 / 0.82$ \\
\hline Gallium Metal & Not Avail. & & 100 & & & & & & & \\
\hline \multicolumn{11}{|l|}{ Liquid: } \\
\hline Gallium Alloy GF & & & 65.00 & 0.05 & 16.00 & & & 18.95 & & \\
\hline Dispersalloy & & 100 & & & & & & & & \\
\hline Tytin & & 100 & & & & & & & & \\
\hline
\end{tabular}

setting for $15 \mathrm{~s}$, and Tytin on the $\mathrm{M}$ setting for $10 \mathrm{~s}$. Cylindrical specimens $(4 \mathrm{~mm}$ in diameter and $3 \mathrm{~mm}$ high) were prepared in a stainless steel mold with a pressure of $14 \mathrm{MPa}$ according to the procedures outlined inANSI/ADA specification \#1 (ADA, 1980). The samples were then aged for $7 \mathrm{~d}$ at $37^{\circ} \mathrm{C}$. Pure gallium specimens were melted at approximately $60^{\circ} \mathrm{C}$ and cast into a vinyl polysiloxane mold. For determination of $\mathrm{Zn}$, separate samples $4 \mathrm{~mm}$ in diameter and $8 \mathrm{~mm}$ high were fabricated to provide more extract volume.

The samples were aged for $1 \mathrm{wk}$ at $37^{\circ} \mathrm{C}$ and were then polished based alloys has also been reported by Kaga et al. (1992b). These investigators also used a filter test to measure the cytotoxicity of a gallium-based alloy to human gingival fibroblasts after $24 \mathrm{~h}$ of exposure. They reported that the galliumbased alloy was less cytotoxic than Dispersalloy, but they did not carry the exposure beyond $24 \mathrm{~h}$. Furthermore, although they measured the cytotoxicity of the individual elements which comprise the gallium-based alloy, they did not measure release of these elements from the samples themselves and were, therefore, only able to speculate about which element might be causing the cytotoxicity.

The purpose of the current study was to use an in vitro screening test to compare the cytotoxicity of dental amalgams to a gallium-based alloy which is used for dental restorations. This test offers several advantages over previous tests. First, by measuring the cytotoxicity of sequential extracts of the samples, trends in the cytotoxic response were identified. These trends were useful in predicting possible longer-term behavior from a short-term test. Second, by measuring the elements which were released into the cell-culture medium at different extraction intervals, trends in the corrosion of the samples were identified. And finally, by correlating the concentrations of released elements with the previous cytotoxicity data on the individual elements (Wataha et al., 1991), the elements which were the most likely causes of the cytotoxicities of these samples were identified.

\section{MATERIALS AND METHODS}

Four materials were tested (Table 1). Gallium Alloy GF (Tokuriki Honten, Tokyo, Japan) was chosen because it has been previously tested in vitro (Kaga et al., 1992b; Psarras et al., 1992). Dispersalloy (Johnson and Johnson, New Brunswick, NJ, USA) and Tytin (Kerr, Romulus, MI, USA) were chosen because they are representative of mercurybased dental amalgams currently used as dental restorations. Pure gallium metal (99.99\%, Johnson and Mathey, Ward Hill, MA, USA) was chosen to facilitate cytotoxicity comparisons with Gallium Alloy GF. Finally, Teflon (Small Parts, Inc., Miami Lakes, FL, USA) was chosen as a negative control. Six replicates of each material were mixed according to the manufacturers' directions. Gallium Alloy GF was triturated using a Vari-Mix III amalgamator (L.D. Caulk, Milford, DE, USA) on the $\mathrm{L}$ setting for $7 \mathrm{~s}$. Dispersalloy was triturated on the $\mathrm{M}$ using clinically relevant procedures. Dispersalloy and Tytin samples were polished on 600 grit silicon carbide paper with water, then final polished with a pumice slurry and tin oxide slurry. Gallium Alloy GF was polished as specified by the manufacturer using medium and fine polishing points with intermittent soaks in water. After polishing, the samples were cleaned and disinfected for cytotoxicity testing by scrubbing each sample with a soft toothbrush and Alconox soap solution, followed by copious rinsing with double-distilled water, submersion in 95\% ethanol, and four rinses with sterile doubledistilled water. The samples were then stored at $25^{\circ} \mathrm{C}$ for $24 \mathrm{~h}$ in a sterile container. The total time between fabrication of the samples and immersion into cell-culture medium was approximately $2 \mathrm{wk}$.

The samples (geometrical surface area of $63 \mathrm{~mm}^{2}$ ) were extracted individually into cell-culture medium as follows. Each sample was submerged in $1.0 \mathrm{~mL}$ of cell-culture medium consisting of Dulbecco's Modified Eagle Medium (Gibco BRL, Grand Island, NY, USA), 3\% NuSerum serum supplement (Collaborative Research, Bedford, MA, USA), 125 units/ $\mathrm{mL}$ of penicillin, $125 \mu \mathrm{g} / \mathrm{mL}$ of streptomycin, $2 \mathrm{mmol} / \mathrm{L}$ glutamine, $10 \mu \mathrm{g} / \mathrm{mL}$ of gentamycin, and $28 \mathrm{mmol} / \mathrm{L}$ of HEPES, $\mathrm{pH}=7.2$ (Gibco BRL). The samples were then incubated $8 \mathrm{~h}$ at $37^{\circ} \mathrm{C}$ in sealed, sterile polyethylene centrifuge tubes. After $8 \mathrm{~h}$, the medium was removed and transferred to a separate vial. Another $\mathrm{mL}$ of medium was added, and the samples were incubated for $40 \mathrm{~h}$. The medium was removed, then replaced, and the samples were incubated for a final $24 \mathrm{~h}$. The cytotoxicity of the extracts (0-8 h, 8-48 h, and 48-72 h) and elements released into them were measured. For determinations of the release of zinc, the $4 \times 8 \mathrm{~mm}$ samples were extracted into $2.0 \mathrm{~mL}$ of medium to maintain the same surface area to volume ratio. Pilot experiments showed that the release of $\mathrm{Zn}$ from either $4 \times 3$ or $4 \times 8 \mathrm{~mm}$ samples was equivalent.

The cytotoxicity of the extracts was tested on Balb/c 3T3 cells (ATCC CCL 163, clone A31, Rockville, MD, USA) because these cells are recommended by the International Standards Organization for cytotoxicity screening (ISO, 1993) and because the investigators had previous data on the cytotoxicity of the individual elements on these cells (Wataha et al., 1991). The cells were cultured and plated into 96-well dishes $\left(0.33 \mathrm{~cm}^{2} /\right.$ well $)$ at 25,000 cells $/ \mathrm{cm}^{2}$ in $200 \mu \mathrm{L}$ of medium. After incubation at $37^{\circ} \mathrm{C}$ and $5 \% \mathrm{CO}_{2}$ for $24 \mathrm{~h}$, the 


\begin{tabular}{|ccccc|}
\hline \multicolumn{4}{|c|}{ TABLE 2: CONDITIONS FOR ATOMIC ABSORPTION DETECTION } \\
\hline Element & Method & $\begin{array}{c}\text { Wavelength } \\
(\mathrm{nm})\end{array}$ & $\begin{array}{c}\text { Slit Width } \\
(\mathrm{nm})\end{array}$ & $\begin{array}{c}\text { Detection } \\
\text { Limit (ppb) }\end{array}$ \\
\hline $\mathrm{Ag}$ & GFA* $^{*}$ & 328.1 & 0.5 & 6.8 \\
$\mathrm{Cu}$ & $\mathrm{GFA}$ & 327.4 & 0.5 & 16.3 \\
$\mathrm{Ga}$ & $\mathrm{GFA}$ & 294.4 & 0.5 & 1600 \\
$\mathrm{In}$ & $\mathrm{GFA}$ & 325.6 & 0.5 & 24 \\
$\mathrm{Hg}$ & $\mathrm{CV}^{* *}$ & 253.7 & 0.5 & 54 \\
$\mathrm{Zn}$ & AA $^{* *}$ & 213.9 & 1.0 & 82 \\
\hline$*$ Graphite Furnace Atomization & & \\
$* * *$ & Cold Vapor Method \\
$* * *$ & Air-Acetylene Flame Atomization & & \\
\hline
\end{tabular}

medium was removed, and $100 \mu \mathrm{L}$ of the alloy extracts were added to each well. After an additional $24 \mathrm{~h}$, the mitochondrial activity of the cells was assessed by measuring the succinic dehydrogenase (SDH) activity. SDH activity was measured using the MTT technique as previously described (Pearse, 1972; Wataha et al., 1991).

The concentration of the elements in the extracts was measured by means of atomic absorption spectrophotometry (Varian Model AA20, Varian, Mulgrave, Australia). Conditions for the analysis and detection limits are listed in Table 2. For the graphite furnace method, samples were diluted to the appropriate concentrations with $10 \% \mathrm{v} / \mathrm{v} \mathrm{HNO}_{3}$, except for silver which was diluted with $40 \% \mathrm{v} / \mathrm{v} \mathrm{HNO}_{3}$. For mercury, the cold vapor method (Dominski, 1985) was employed using a cold vapor generator (VGA-76, Varian), and samples were diluted with $5 \%$ by volume $\mathrm{HNO}_{3}$ and $5 \%$ by volume $\mathrm{HCl}$. For the air-acetylene flame method, $30 \% \mathrm{HNO}_{3}$ was used as a diluent.

The cytotoxicity of the extracts was calculated by expressing the SDH activity of the cells as a percentage of the Teflon negative controls. Three standard errors of the mean were used to represent $95 \%$ confidence intervals of these values. Differences between the cytotoxicities were assessed using ANOVA and Tukey multiple comparison intervals $(p=0.05)$. The concentrations of elements released into the cell-culture medium were averaged, and three standard errors of the means were computed.

\section{RESULTS}

The Tytin extracts were not significantly different in cytotoxicity from Teflon in any of the extraction intervals (Fig. 1). Dispersalloy extracts were severely toxic for the $0-8$ and 8-48 $\mathrm{h}$ intervals, but were only moderately toxic for the 48-72 h interval. Gallium Alloy GF extracts were moderately toxic for all intervals, but the cytotoxicity increased from a $25 \%$ depression at $0-8 \mathrm{~h}$ to more than $45 \%$ at the $8-48$ and 48-72 $\mathrm{h}$ intervals. The gallium metal was moderately toxic at all three intervals.

The Tytin samples released levels of mercury which were generally below the detection limits, but released low levels of silver and significant levels of $\mathrm{Cu}$, especially in the $0-8 \mathrm{~h}$ interval (Table 3). Little or no $\mathrm{Zn}$ release was detected. Dispersalloy samples released low levels of mercury, and levels of $\mathrm{Cu}$ and $\mathrm{Ag}$ which were lower than for the Tytin samples. However, Dispersalloy released significant levels of $\mathrm{Zn}$ in the initial intervals (0-8 and 8-48 h). Gallium Alloy GF samples

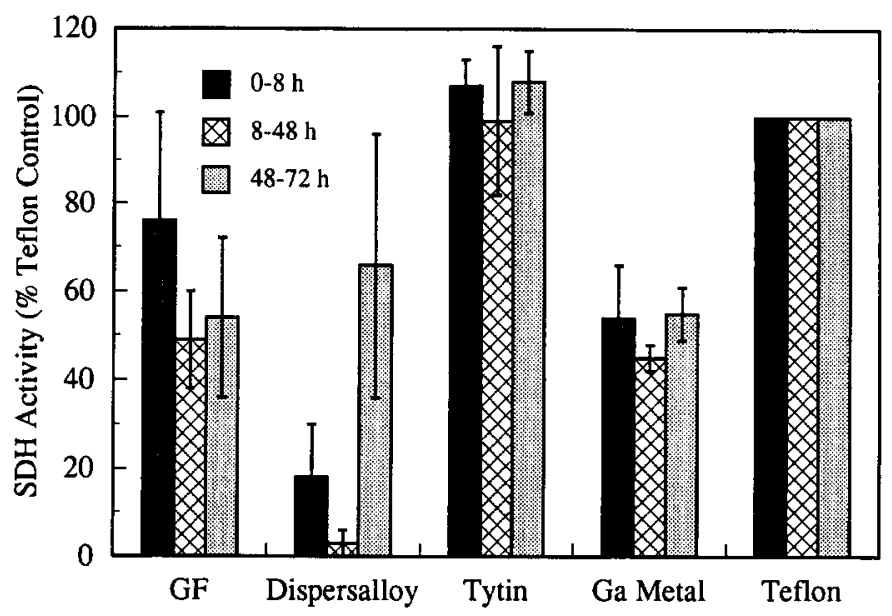

Fig. 1. Cytotoxicity of extracts of gallium- and mercury-based dental alloys. Extraction intervals were 0-8, 8-48, 48-72 $\mathrm{h}$. Balb/c $3 \mathrm{~T} 3$ mouse fibroblasts were exposed to the extracts for $24 \mathrm{~h}$. The succinic dehydrogenase (SDH) activity was measured and expressed as a percentage of the Teflon negative control. Error bars are three standard errors of the mean. ANOVA (with Tukey multiple comparison intervals at $p=0.05$ ) showed that Teflon and Tytin were not different in any time interval, but that Gallium Alloy GF (GF) and the Ga metal were significantly more cytotoxic than Teflon in all intervals. Dispersalloy extracts were significantly more cytotoxic than GF only for the 0-8 and 8-48 h intervals.

released $>7000$ parts per billion ( $\mathrm{ppb}$ ) of gallium in all intervals, but lower levels of $\mathrm{Ag}, \mathrm{Cu}$, and In. The levels of $\mathrm{Ag}$ and $\mathrm{Cu}$ were slightly higher in the $0-8 \mathrm{~h}$ interval. Palladium and zinc were not measured in the Gallium Alloy GF extracts because the release of these elements was below detectable levels in preliminary experiments. The gallium metal released $>17,000 \mathrm{ppb}$ of gallium in all intervals. Zinc at concentrations of $130 \mathrm{ppb}$ was detected in the Teflon extracts as expected, but concentrations of the other elements in the native medium were below detection limits (Table 2). Because of severe matrix interferences, the concentrations of tin were not measured in any of the extracts.

For the Dispersalloy and Tytin samples, the release rates were the highest from $0-8 \mathrm{~h}$ for $\mathrm{Ag}$ and $\mathrm{Cu}$, but increased slightly for $\mathrm{Zn}$ (Table 4). The rate of release of $\mathrm{Zn}$ was ten times less for Tytin than for Dispersalloy, while the release of $\mathrm{Cu}$ was ten times greater for Tytin than for Dispersalloy. For the Gallium Alloy GF samples, the rates of release showed no clear pattern, but did not decrease over time. The release of Ga from gallium metal was faster in the 0-8 $\mathrm{h}$ interval than for the Gallium Alloy GF samples, but was roughly equivalent thereafter. Rates of $\mathrm{Hg}$ release were not calculated because the release of $\mathrm{Hg}$ was at or below detection limits.

\section{DISCUSSION}

To determine which element(s) were contributing to the cytotoxicity of these materials, the concentrations of elements released (Table 3) were compared with the concentrations of the elements required to cause a 50\% reduction in SDH activity (Table 5), which were published previously (Wataha et al., 1991). Tytin showed little or no cytotoxicity in spite of significant $\mathrm{Cu}$ release. However, the levels of $\mathrm{Cu}$ required $(>15,000 \mathrm{ppb})$ to cause inhibition of SDH activity were not present in the extracts (Wataha et al., 1991). Similarly, levels of $\mathrm{Ag}$ and $\mathrm{Zn}$ did not approach toxic levels in any interval. For Dispersalloy, the levels of $\mathrm{Ag}$ and $\mathrm{Cu}$ which were released were not sufficient to cause cytotoxicity, but the levels of $\mathrm{Zn}$ 


\begin{tabular}{|c|c|c|c|c|c|c|}
\hline $\begin{array}{l}\text { Extraction } \\
\text { Period (h) }\end{array}$ & $\mathrm{Hg}$ & $\mathrm{Ga}$ & $\mathrm{Ag}$ & $\mathrm{Cu}$ & $\ln$ & $\mathrm{Zn}$ \\
\hline \multicolumn{7}{|c|}{ Gallium Alloy GF } \\
\hline $0-8$ & & $7000 \pm 4000$ & $42 \pm 27$ & $260 \pm 140$ & $100 \pm 70$ & NM \\
\hline $8 \cdot 48$ & & $22000 \pm 8000$ & $24 \pm 14$ & $50 \pm 28$ & $1680 \pm 900$ & NM \\
\hline $48-72$ & & $24000 \pm 8000$ & $20 \pm 15$ & $55 \pm 50$ & $600 \pm 250$ & NM \\
\hline \multicolumn{7}{|c|}{ Dispersalloy } \\
\hline $0-8$ & $16 \pm 15$ & & $22 \pm 5$ & $185 \pm 76$ & & $730 \pm 240$ \\
\hline $8 \cdot 48$ & $90 \pm 30$ & & $40 \pm 19$ & $200 \pm 220$ & & $1300 \pm 400$ \\
\hline $48-72$ & $5 \pm 5$ & & $21 \pm 16$ & $100 \pm 50$ & & $470 \pm 460$ \\
\hline \multicolumn{7}{|c|}{ Tytin } \\
\hline 0.8 & $20 \pm 10$ & & $35 \pm 27$ & $1740 \pm 500$ & & $131 \pm 17$ \\
\hline $8-48$ & $46 \pm 42$ & & $26 \pm 17$ & $1600 \pm 600$ & & $160 \pm 60$ \\
\hline $48-72$ & $9 \pm 6$ & & $32 \pm 38$ & $270 \pm 80$ & & $190 \pm 15$ \\
\hline \multicolumn{7}{|c|}{ Gallium Metal } \\
\hline $0-8$ & & $17000 \pm 600$ & & & & \\
\hline $8-48$ & & $28000 \pm 700$ & & & & \\
\hline $48-72$ & & $21000 \pm 300$ & & & & \\
\hline
\end{tabular}

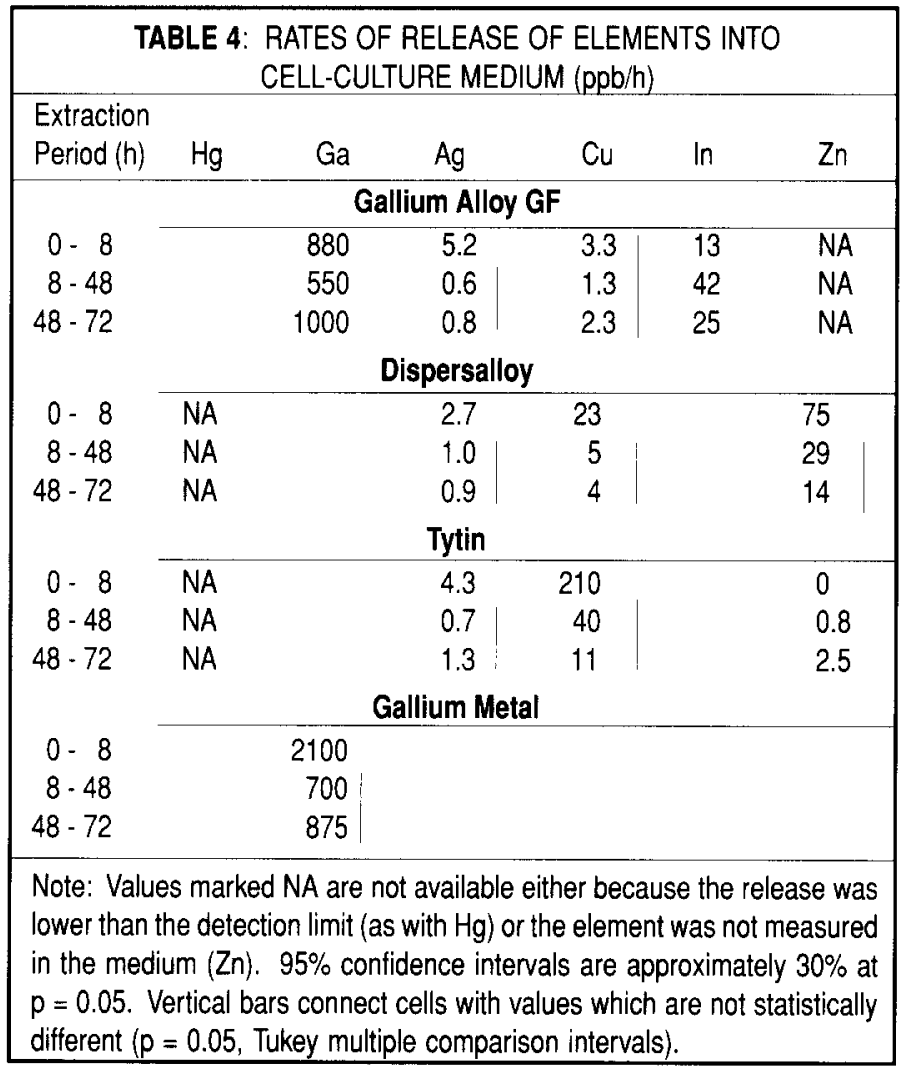

( 730 and $1300 \mathrm{ppb}$ at $0-8$ and $8-48 \mathrm{~h}$, respectively) approached cytotoxic levels (Table 5) and were most likely responsible for the cytotoxicity. The cytotoxicity of the samples decreased somewhat in the 48-72 $\mathrm{h}$ interval when the concentration of released $\mathrm{Zn}$ decreased. For Gallium Alloy GF, the amount of $\mathrm{Ga}$ released was more than sufficient to cause $100 \%$ toxicity (Table 5), but levels of $\mathrm{Ag}, \mathrm{Cu}$, and In were insignificant. The toxicity of the gallium-alloy extracts was somewhat less than might be expected since the released Ga levels were greater

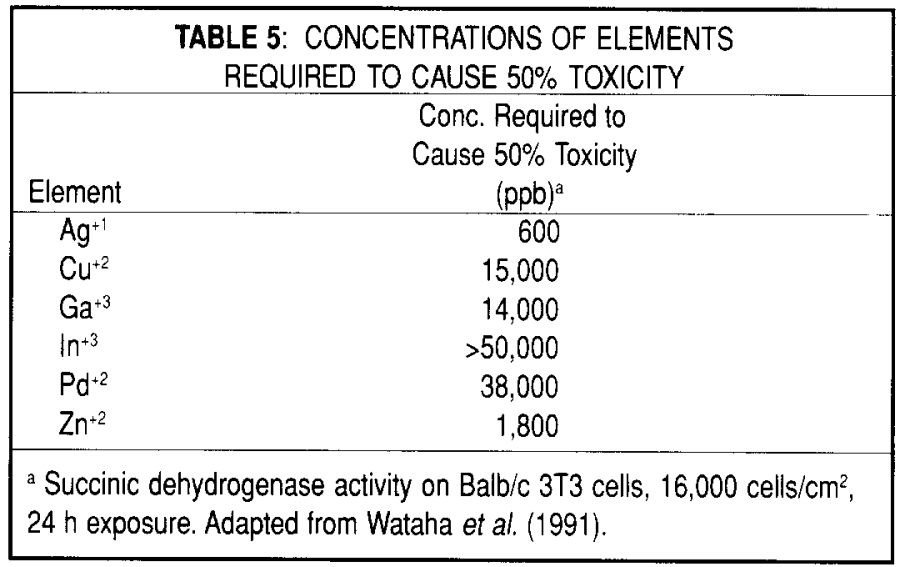

than those required to cause $50 \%$ toxicity. The reduced cytotoxicity of gallium-based alloy in the current study may have been caused by the higher cell densities $\left(25,000\right.$ cells $\left./ \mathrm{cm}^{2}\right)$ which were used compared to previous investigations ( 16,000 cells/ $\mathrm{cm}^{2}$ ) (Wataha et al., 1991). It has been shown that for $\mathrm{Ga}$, higher cell densities significantly reduce the toxic response of Balb/c 3T3 cells (Wataha et al., 1993). The gallium metal released levels of gallium which were also cytotoxic. The toxicity of the $0-8 \mathrm{~h}$ extracts was greater for the gallium metal than for the gallium-based alloy, which correlated well with the higher release of $\mathrm{Ga}$ from the metal $v s$. the alloy in this interval. Furthermore, for the 8-48 and 48-72 $\mathrm{h}$ intervals, the amount of gallium released correlated with the cytotoxicities of the gallium metal or alloy. In these intervals, the cytotoxicities were not statistically different.

The current study demonstrated that the use of multiple extraction intervals combined with knowledge about which elements were released was valuable in projecting longer-term cytotoxicity behavior from short-term tests. In the 0-8 and 8-48 h extraction intervals, the cytotoxicity of Gallium Alloy GF was greater than that of Tytin, but less than Dispersalloy. However, in the 48-72 $\mathrm{h}$ extraction interval, the cytotoxicity of 
Dispersalloy was reduced because the $\mathrm{Zn}$ release was decreasing. Thus, the longer-term trend in cytotoxicity favored Dispersalloy over Gallium Alloy GF because the release of elements from Dispersalloy was decreasing, whereas the release of $\mathrm{Ga}$ from the gallium-based alloy and its cytotoxicity showed no signs of decreasing. Longer-term tests are needed to verify these observations.

This work agrees with reports that the cytotoxicity of Gallium Alloy GF was less than that of Dispersalloy after $24 \mathrm{~h}$ (Kaga et al., 1992b). However, because of the long-term trends in the release of elements, a $24 \mathrm{~h}$ test by itself is probably not predictive of longer-term behavior. In contrast, the results of the current study did not agree with other work which has shown that gallium-based alloy samples were no more cytotoxic than those from Dispersalloy even after $7 \mathrm{~d}$ of extraction (Psarras et al., 1992). It is possible that the precorrosion of samples in saline used by these investigators or differences in cell-culture variables were responsible for these discrepancies. The results of the current study also agree with several groups who have reported that galliumbased alloys show severe corrosion and disintegration of samples when implanted subcutaneously in animals for up to 6 mon (Lyon et al., 1966; Langeland et al., 1967; Kaga et al., 1992a). The current study shows that Gallium Alloy GF released substantial amounts of gallium which did not abate after $72 \mathrm{~h}$ of exposure to cell-culture medium. This finding correlates well with the behavior of these alloys in vivo for periods up to $6 \mathrm{mon}$. The significant corrosion of these alloys observed in the current study also correlated well with reports of significant tarnish, roughness, and discoloration in Ga-based alloys which have been placed intraorally (Kim et al., 1988; Yamashita et al., 1989; Den et al., 1991).

In conclusion, the current study demonstrated that a $72 \mathrm{~h}$ test for measuring in vitro cytotoxicity was successful in discriminating between dental amalgam and gallium-based alloys. The use of sequential extracts over the $72 \mathrm{~h}$ period permitted observation of trends in both the elemental release from the materials and their cytotoxicities, and these trends correlated well with in vivo tests which have been previously published (Langeland et al., 1967; Kaga et al., 1992b; Kim et al., 1988; Yamashita et al., 1989; Den et al., 1991; Navarro et al., 1993). The cytotoxicity of Tytin was low throughout all extraction intervals, which correlated well with the low concentrations of elements released from this material. The cytotoxicity of Dispersalloy was severe initially, but improved between 48 and $72 \mathrm{~h}$ as the $\mathrm{Zn}$ release decreased. The cytotoxicity of Gallium Alloy GF was moderate initially but increased after $8 \mathrm{~h}$, which correlated with a substantial and persistent Ga release from this material. This design of the cytotoxicity test reported here should be useful in evaluating new formulations of gallium-based and other dental restorative materials which are developed.

\section{ACKNOWLEDGMENTS}

The investigators gratefully acknowledge the support of the National Institutes of Health through Grants DE-10178 and DE-09296. The authors also thank Tokuriki Honten (Tokyo, Japan) for supplying the gallium-based alloy, and Ms. Lois Rockwell for her expert assistance with the atomic absorption spectrophotometry.
Received May 20, 1994 /Accepted August 17, 1994

Address correspondence and reprint requests to:

John C. Wataha

University of Michigan School of Dentistry

Department of Prosthodontics

1011 N. University Avenue

Ann Arbor, MI 48109-1078 USA

\section{REFERENCES}

ADA (1980). Council on Dental Materials, Instruments, and Equipment. Addendum to American National Standards Institute/American Dental Association Specification No. 1 for Alloy for Dental Amalgam. J Am Dent Assoc 100:246.

Aoki Y, Lipsky MM, Fowler BA (1990). Alteration in protein synthesis in primary cultures of rat kidney proximal tubule epithelial cells by exposure to gallium, indium, and arsenite. Toxicol Appl Pharmacol 106:462-468.

deFreitas JA (1976). A survey of the elemental composition of alloy for dental amalgams. Aust Dent J 24:17-25.

Den M, Fujii H, Machida Y (1991). Clinical study of gallium alloy restoration for children. Shikwa Gakuho 91:947-953.

Domingo $\Omega$, Llobet JM, Corbella J (1987). Acute toxicity of gallium in rats and mice. $J$ de Toxicologie Clinique et Experimentale 7:411-418.

Dominski P (1985). Automated cold vapor determination of mercury: EPA stannous chloride methodology. Varian Instruments at Work AA51, Varian.

FermVH, Carpenter SJ (1970). Teratogenic and embryopathic effects of indium, gallium, and germanium. Toxicol Appl Pharmacol 16:166-170.

Foster BJ, Clagett-Carr K, Hoth D, Leyland-Jones B (1986). Gallium nitrate: The second metal with clinical activity. Cancer Treat Rep 70:1311-1319.

Horibe T, Okamoto Y, Naruse S (1986). Gallium alloys for dental restorations. Part 1. Physical properties of gallium alloys. J Fukuoka Dent Coll 12:198-204.

ISO (1993). Biological evaluation of medical devices. Part 5: Tests for cytotoxicity: In vitro methods. International Standards Organization.

Kaga M, Ohkawa S, Hanawa T, Oguchi H (1992a). Comparative evaluation of biocompatibility of gallium alloy and amalgams in rat subcutaneous tissue.J Jap Soc Dent Mater 11:740-745.

Kaga M, Sakai T, Fujita M, Oguchi H (1992b). Comparative cytotoxic evaluation of gallium alloys and amalgams in cell culture. Pediatric Dent $J$ 2:109-114.

Kawahara H, Yamagami A, Nakamura M (1968). Biological testing of dental materials by means of tissue culture. Int Dent J 18:443-467.

Kim HW, Yada I, Ozaki M, Tsukamoto S, Toshida Y, Okamoto Y, Horibe T (1988). The clinical observation of gallium alloy as a new dental restorative material for primary teeth. J Fukuoka Dent Coll 14:395-400.

Langeland LK, Yoshiki S, Langeland K(1967). Biologic evaluation of a gallium alloy. $J$ Dent Res 46:42, Abstr. No. 24 .

Lyon HW, Waterstrat RM, Paffenbarger GC (1966). Soft tissue response to implant of gallium alloys and silver amalgam alloys. J Am Dent Assoc 72:659-664. 
Navarro M, Franco E, Bastos P, Carvalho R, Teixeria L (1993). Clinical evaluation of gallium alloy. J Dent Res 72:219, Abstr. No. 925.

Okamoto Y, Horibe T (1991). Liquid gallium alloys for metallic plastic fillings. Br Dent $J$ 170:23-26.

Pearse AG (1972). Histochemistry, Theoretical and Applied. Vol 2. Baltimore:Williams and Wilkins, Chapter 20.

Psarras V, Wennberg A, Dérand T (1992). Cytotoxicity of corroded gallium and dental amalgam alloys. Acta Odontol Scand 50:31-36.

Sakai T, Kaga M, Oguchi H (1993). Two-year clinical observation of gallium alloy in pediatric patients. Transactions of the Second International Congress on Dental Materials, 191, Abstr. No. P053.

Smith DL, Caul HJ (1956). Alloys of gallium with powdered metals as possible replacement for dental amalgam. $J A m$ Dent Assoc 53:315-324.
Smith DL, Caul HJ, Sweeney WT(1956). Some physical properties of gallium-copper-tin alloys. JAm DentAssoc 53:677685.

Wataha JC, Hanks CT, Craig RG (1991). The in vitro effects of metal cations on eukaryotic cell metabolism. I Biomed Mater Res 25:1133-1149.

Wataha JC, Hanks CT, Craig RG (1993). The effect of cell monolayer density on the cytotoxicity of metal ions which are released from dental alloys. Dent Mater 9:172-176.

Waterstrat RM (1969). Evaluation of a gallium-palladium-tin alloy for restorative dentistry. J Am Dent Assoc 78:536541.

Waterstrat RM, Longton RW (1964). Gallium-palladium alloys as dental filling material. Pub Health Rep 79:638-642.

Yamashita T, Itoh K, Wakumoto S (1989). Clinical study of an experimental gallium containing alloy. Dent Mater $J$ 8:135140. 